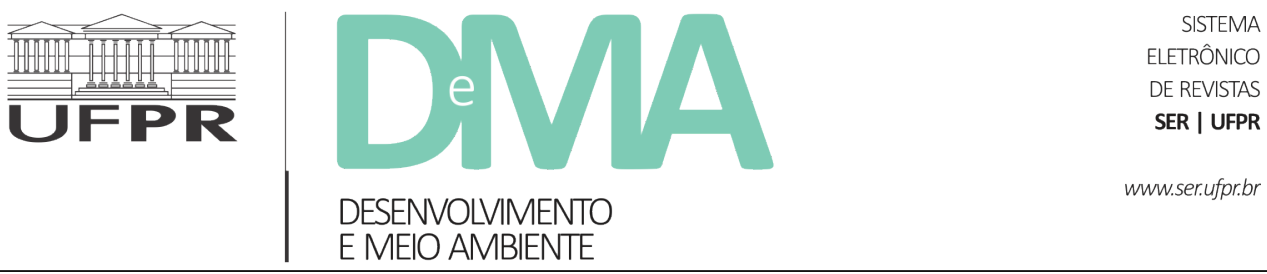

\title{
Reservas extrativistas marinhas: reflexões sobre desafios e oportunidades para a cogestão em áreas marinhas protegidas
}

\section{Marine extractive reserves: reflections on challenges and opportunities for co-management in marine protected areas}

\author{
Paula Chamy Pereira da $\operatorname{COSTA}^{1^{*}}$ \\ ${ }^{1}$ Núcleo de Estudos e Pesquisas Ambientais (Nepam), Universidade Estadual de Campinas (Unicamp), Campinas, SP, Brasil. \\ *E-mail de contato: paula.chamy@gmail.com
}

Artigo recebido em 10 de abril de 2018, versão final aceita em 15 de agosto de 2018.

RESUMO: Este artigo concentra-se na análise das reservas extrativistas, em especial as reservas extrativistas marinhas, instrumento de cogestão criado no Brasil a partir dos conflitos que envolveram variáveis de pobreza e conservação do ambiente natural e que, inicialmente concebidas para ambiente florestal, foram ampliadas para outros ecossistemas. Como alternativa aos modelos restritivos de conservação importados do primeiro mundo, a concepção de reservas extrativistas, em sua gênese, dirige-se ao atendimento simultâneo de princípios de qualidade social e ambiental. No entanto, em que pese o fato desse tipo de área protegida proporcionar múltiplas possibilidades de inserção social e oportunidades para a cogestão colaborativa e adaptativa de recursos naturais de uso comum (em especial os recursos pesqueiros), não se trata de uma panaceia. Existem muitas variáveis que devem ser consideradas em sua criação e implantação, em especial o entendimento das populações beneficiadas sobre direitos e responsabilidades da gestão compartilhada. O objetivo do artigo é refletir sobre algumas perspectivas desse instituto que tem vinte de oito anos de existência, mas que ainda oferece dúvidas sobre a utilização sustentável dos recursos do mar e reais benefícios para as comunidades costeiras.

Palavras-chave: recursos marinhos; comunidades locais; arranjos informais.

ABSTRACT: This article is focused on the analysis of Extractive Reserves, especially the Marine Extractive Reserves, an instrument of co-management created in Brazil stemming from conflicts related to poverty and conservation of the natural environment and which, initially, conceived for the forest environment, was expanded to other ecosystems. As an alternative to the restrictive models of conservation imported from first world countries, 
the conception of extractive reserves, in its genesis, is directed to the simultaneous attendance of social and environmental quality principles. However, despite the fact that this type of protected area provides multiple possibilities for social insertion and opportunities for collaborative and adaptive co-management of natural resources in common use (especially fish resources), it is not a panacea. There are many variables that should be considered in its creation and implementation, especially the understanding of the beneficiary populations on the rights and responsibilities of shared management. The objective of the article is to reflect on some perspectives of this institute, which is twenty-eight years old, but still leaves doubts about the sustainable use of sea resources and real benefits for coastal communities.

Keywords: marine resources; traditional communities; informal arrangements.

\section{Areas marinhas protegidas: por que e para quem?}

Ecossistemas marinhos encontram-se sob inúmeros fatores de degradação ambiental e social. Não podemos retornar às condições prístinas dos oceanos quando inexistia a influência antrópica, mas o interesse na saúde e riqueza dos mares ultrapassa motivações políticas e econômicas (seja para finalidades tróficas, lúdicas, farmacêuticas, energética ou outras) para a recuperação dos estoques e qualidade das áreas marinhas. O bem-estar das sociedades humanas, independentemente de residirem em regiões costeiras ou viverem diretamente dos recursos do mar, depende da conservação desses ecossistemas responsáveis, inclusive pela absorção de um terço das emissões humanas de gás carbônico e regulação do clima (Sabine et al., 2004).

Além de todos os seres vivos dependerem indiretamente da saúde dos ecossistemas marinhos, existem milhões de pessoas ao redor do mundo que dependem diretamente dos recursos do mar (e.g. pescadores de pequena escala, marisqueiras, cultivadores de algas). Para essa parcela da população mundial, o extrativismo dos recursos marinhos, com toda a diversidade existente nessa atividade, contribui para a segurança alimentar, sobrevivência e desenvolvimento de seus modos de vida.

Há décadas as condições dos mares não são favoráveis. Segundo projeções da Plataforma Intergovernamental sobre Biodiversidade e Serviços Ecossistêmicos (IPBES, 201819), que avaliou a diversidade biológica e serviços ecossistêmicos de todo o planeta, somente $25 \%$ da superfície terrestre permanece livre dos impactos das atividades humanas, lembrando que o relatório não abarcou os polos e oceanos abertos. Estudos diversos, no entanto, evidenciam a depleção/exaustão dos estoques pesqueiros, aumento dos níveis de poluição (Earle, 2017) e destacam a necessidade de instituir ferramentas para conservação marinha (Halpern \& Warner, 2002; Steward et al., 2009).

A Convenção sobre Diversidade Biológica (CDB) de 2010, realizada no Japão, por meio da meta de Aishi número 11, estabeleceu que os países signatários protegessem $10 \%$ das áreas marinhas até 2020. Em março de 2018, o Brasil que vinha a passos lentos na observação dessa meta, resolveu a questão por meio da criação da Área de Proteção Ambiental (APA) e Monumento Natural nas regiões do Arquipélago São Pedro e São Paulo em Pernambuco e do Arquipélago de Trindade e Martin Vaz

\footnotetext{
${ }^{1}$ Disponível em: <http://www.ipbes.net/news/media-release-biodiversity-nature's-contributions-continue-dangerous-decline-scientists-warn>. Acesso em: abr. 2018.
} 
no Espírito Santo, alcançando a porcentagem de $25 \%$ de áreas marinhas protegidas (decretos $9313 \mathrm{e}$ 9312/2018 respectivamente). Para um país que possuía 1,5\% de áreas marinhas protegidas até então, esse aumento poderia indicar uma real preocupação com a saúde dos oceanos e das populações que dele dependem diretamente.

No que diz respeito especificamente às comunidades pesqueiras e áreas marinhas por elas acessadas, existem ainda políticas públicas de pesca mal adaptadas e em desacordo com práticas cotidianas e regras locais, o que, além de agravar as condições de pobreza desses grupos, compromete a busca por soluções para problemas que envolvem a conservação dos ecossistemas marinhos e melhoria da qualidade de vida.

Diante de uma crise global, acordos e políticas multilaterais para conter a degradação dos ecossistemas marinhos e costeiros foram estabelecidos, entre eles os Objetivos do Desenvolvimento Sustentável de 2015, que, além de ratificar o estabelecimento de mínimo $10 \%$ das zonas costeiras e marinhas em todo o mundo até 2020, pretende fomentar a implementação de medidas de restauração, combater a acidificação dos oceanos e eliminar a sobrepesca.

Como ferramenta para conter a degradação dos ecossistemas marinhos e costeiros, áreas marinhas protegidas (AMPs) têm sido criadas em todo o mundo. AMPs são definidas pela União Internacional para a Conservação da Natureza (IUCN, 2012) como qualquer área entre marés ou abaixo da linha d'água, juntamente à água sobrejacente a sua flora, fauna e características históricas e culturais associadas que tem sido reservada por lei ou outra forma efetiva para proteger parte ou todo ambiente envolvido, com potencial para fortalecer dinâmicas territoriais de desenvolvimento (Carrière \& Cazella,
2006) e promover a participação de organizações da sociedade civil nas políticas públicas.

Em todo o mundo, esforços para a proteção dos ecossistemas marinhos levaram à criação de parques, reservas e áreas de conservação. O Atlas Espacial Marinho aponta para a existência de mais de 11 mil AMPs no mundo e muitas outras em diversos estágios de criação. Existem vários tipos de AMPs com distintos objetivos de criação, contextos ecológicos e sociais, grau de envolvimento dos usuários, tamanho, manejo, formas de gestão, entre outros fatores (Pendleton et al., 2017) e os sucessos e fracassos oferecem oportunidades de aprendizado para obtenção de resultados sociais e ecológicos satisfatórios.

$\mathrm{Na}$ esfera formal e como experimento científico, refúgios e normas de proteção para os oceanos não são novidade. Roberts (2007) cita, entre outros exemplos, a proibição da pesca de arrasto nas proximidades de Marselha, na França, entre 1793 e 1830, os experimentos realizados na Escócia no final do século XIX, e a "teoria das reservas" do cientista francês Marcel Hérumbel. No Chile, Filipinas e Nova Zelândia, instrumentos para proteção dos oceanos surgiram na década de 1970, mas, como destaca Johannes (1982), sem a concordância com os costumes locais, tais áreas estão fadadas ao insucesso.

A importância do apoio da sociedade às AMPs de proteção integral foi destacada por Aburto-Oropeza et al. (2011), que constataram que em dez anos, com a participação das comunidades locais, a quantidade de pescado quintuplicou com a criação do parque nacional Cabo Pulmo no Oeste do México. No entanto, sem participação social, a eficácia das AMPs pode ficar comprometida a longo prazo (Basurto, 2017). 
No Brasil, áreas marinhas de proteção integral (no-take) existem há décadas na forma de reservas biológicas (e.g. Atol das Rocas criada em 1979) e parques nacionais (e.g. Abrolhos/BA criado em 1983) e estaduais marinhos (e.g. Parcel Manuel Luís/MA criado em 1991). Em estudo sobre 87 AMPs de proteção integral, Edgar et al. (2014) relacionaram o potencial de sucesso ecológico dessas áreas a cinco características principais que decorrem do planejamento e gestão: i) grau de pesca permitido no interior das AMPs; ii) nível de execução; iii) idade da AMP; iv) tamanho da AMP; e v) existência de habitat contínuo que permita a mobilidade das espécies dentro dos limites da área protegida marinha. Mas, além das áreas no-take, AMPs são também ferramentas para o manejo de pesca e instituídas como modalidade de uso sustentável. Reservas extrativistas marinhas (ResexMar) inserem-se nessa categoria.

No Brasil, um movimento de mobilização de populações culturalmente diferenciadas para proteção de seus direitos sobre territórios e recursos naturais modificou o cenário de proteção integral das áreas protegidas com a instituição das reservas extrativistas (Resex). Inicialmente pensado para ecossistemas florestais, esse modelo de área protegida foi transposto para o ecossistema marinho dois anos após a implantação da primeira reserva extrativista florestal. As ResexMar correspondem a um instrumento público voltado ao espaço marinho que visa a favorecer a criação e consolidação de estratégias territoriais de conservação e proteção do direito consuetudinário de pescadores artesanais (forma genérica que inclui diferentes categorias como coletores de marisco e caranguejo) em aliança (e cogestão) com o Estado.
Desse modo, as ResexMar, em sua conformação, têm potencial para promover a incorporação dos arranjos informais locais nas políticas públicas de manejo dos recursos marinhos, sendo necessário refletir sobre alguns desafios e oportunidades para que haja avanços nesse instituto que já conta com quase três décadas de existência.

\section{A gênese das reservas extrativistas marinhas}

O extrativismo é uma atividade secular que garante aos povos que dependem diretamente da prodigalidade da natureza não somente a subsistência, mas, ao menos em parte, alguma autonomia. A Resex corresponde a uma área delimitada para a prática de atividade de extração de recursos naturais concebida no final da década de 1980 em decorrência dos violentos conflitos sobre legitimidade e regularização fundiária das terras historicamente habitadas por populações extrativistas amazônicas (Chamy, 2005), particularmente seringueiros.

O trabalho dos seringueiros foi responsável pelas exportações de borracha no final do século XIX, mas, após um período de ascensão, a produção nacional de borracha atravessou diversos períodos de crise. Em 1912, por exemplo, a crise da borracha deveu-se à concorrência do produto oriundo da Malásia, fruto de biopirataria decorrente do contrabando de sementes de seringueira da Amazônia para o Sudeste asiático e que levou à falência empresas exportadoras de borracha em Belém e Manaus. A Segunda Guerra Mundial impulsionou novamente a exportação de borracha, mas foi monopolizada pelo Governo Federal, que incentivou a migração de milhares de nordestinos para a região amazônica como mão de obra para os seringais. 
Na década de 1970, programas governamentais para ocupação das fronteiras e promoção de desenvolvimento tecnológico e agropecuário (Grande Carajás, Calha Dorte, Radambrasil, Projeto Jari, Codeara, entre outros) incentivaram a migração de atores sociais diversos e com outro declínio das exportações da borracha, latifundiários venderam suas terras para empresas madeireiras, empresas mineradoras e agropecuárias, o que levou a expulsão de milhares de seringueiros das áreas produtivas.

Sem título de propriedade, mas dependentes diretos do extrativismo da borracha, os seringueiros organizaram os empates, pleiteando, como posseiros, a propriedade da terra das quais dependiam para sobreviver (Chamy, 2005). Segundo Chico Mendes (1990), o empate foi a estratégia encontrada pelos seringueiros para se "organizarem em mutirões e se deslocarem para os locais de desmatamento, se colocarem entre os peões e a florestas e desmobilizar seus acampamentos, dialogar com eles e forçar a retirada".

O movimento dos seringueiros levou para as esferas internacionais os problemas socioambientais nacionais e denunciou sérias violações aos direitos humanos, como os recorrentes assassinatos e supressão de direitos fundamentais (Cunha, 2001). O caráter unificador do movimento dos seringueiros levou à criação, em 1985, do Conselho Nacional dos Seringueiros (CNS), que agregou ribeirinhos, quilombolas, indígenas, castanheiras, além de múltiplos setores interessados em contribuir para a garantia de direitos dessas populações (e.g. ambientalistas, técnicos e cientistas).

Dois anos depois, o Programa Nacional de Reforma Agrária do Instituto nacional de Colonização e Reforma Agrária (Incra) lançou a portaria 627/1987 e criou o Projeto de Assentamento Ex- trativista - PAE (Allegretti, 1994), instrumento da política fundiária que concedia lotes individuais para cada família e versava sobre a função social da propriedade. Os seringueiros resistiram à divisão dos seringais em lotes estabelecidos pelo PAE e, nos moldes das reservas indígenas, reivindicaram títulos coletivos de usufruto sobre os seringais (Cunha \& Almeida, 2002).

Com o fortalecimento do debate ambiental da década de 1980 (nessa década foram promulgadas a Lei Nacional do Meio Ambiente, Lei 6.938/1981, Plano Nacional de Gerencialmente Costeiro, Lei 7.661/1998 e a própria Constituição Federal de 1988, que confere diretamente tratamento constitucional para a proteção do meio ambiente), as discussões dos problemas intestinos do CNS foram integradas pelo Programa Nacional do Meio Ambiente (PNMA) de 1989 e o extrativismo deixou a esfera fundiária e passou a integrar a política ambiental nacional.

Enquanto no Incra os assentamentos extrativistas dependiam de concessão de uso, cabendo à comunidade concessionária decidir sobre a forma de gestão a ser adotada nas áreas assentadas, desde que incluídas medidas de conservação para a atividade extrativa, no campo ambiental, o PNMA (Lei 7.804/1989) instituiu que esses espaços territoriais fossem especialmente tutelados pelo poder público, o que pode ser apontado como uma interferência na autonomia das comunidades outorgadas.

Uma importante alteração repousa sobre o fato de que enquanto no Incra os assentamentos dependiam de terras livres e desembaraçadas para implantação das já denominadas reservas extrativistas, na esfera ambiental não havia condicionantes fundiárias, cabendo ao Instituto Brasileiro do Meio Ambiente (Ibama) realizar as desapropriações 
necessárias (Chamy, 2005) e gerir o território juntamente com a comunidade outorgada (outorga coletiva).

Outros aspectos que merecem destaque na mudança do campo fundiário para o ambiental são: o direito de uso coletivo, proibição de transmissão inter vivos, necessidade de um plano de manejo aprovado pelo órgão ambiental e formação de conselho deliberativo para auxiliar na gestão da Resex. Após uma longa e violenta trajetória histórica, como modelo de área protegida pensado e criado originalmente na esfera nacional, as Resex foram reconhecidas definitivamente pela política ambiental com a promulgação do Sistema Nacional de Unidades de Conservação (Snuc, Lei 9.985, de 18/06/2000, regulamentada pelo Decreto 4.340, de 22/08/2002).

Pelo Snuc o extrativismo consiste no: "sistema de exploração baseado na coleta e extração, de modo sustentável, de recursos naturais renováveis" (art. 2, XII). As Resex são definidas como: "área utilizada por populações extrativistas tradicionais, cuja subsistência baseia-se no extrativismo e, complementarmente, na agricultura de subsistência e na criação de animais de pequeno porte, e tem como objetivos básicos proteger os meios de vida e a cultura dessas populações, e assegurar o uso sustentável dos recursos naturais da unidade" (artigo 18). Para Diegues (2008), as reservas extrativistas marinhas podem ser consideradas um novo tipo de commons, uma vez que têm limites definidos e existe o comanejo da pesca acordado entre poder público e usuários diretos.

A criação das Resex, sejam elas florestais ou marinhas, necessita de reivindicação por parte de população tradicional (aquelas que atendem aos requisitos do Decreto 6.040/2007, a Política Nacional dos Povos e Comunidades Tradicionais - PNPCT) devidamente organizada à Comissão Nacional de Desenvolvimento Sustentável dos Povos e Comunidades Tradicionais (CNPCT), órgão do Ministério do Meio Ambiente (MMA).

Um plano de manejo definindo regras de uso das atividades a serem desenvolvidas nos limites da reserva extrativista é elaborado pelos interessados. A responsabilidade pelo plano de manejo que era do Ibama foi transferida para o Instituto Chico Mendes de Conservação da Biodiversidade (ICMBio) quando esse órgão foi criado em 2007. No mesmo ano a instrução normativa (IN) 2/2007 do ICMBio disciplinou as normas para composição dos conselho deliberativos (coletivo formado por conselheiros oriundos dos setores interessados, como: órgãos da administração pública, forças armadas, universidades, organizações não governamentais, associações) das Resex, determinando que mais da metade (metade mais um) dos representantes desse conselho fosse oriundo das comunidades extrativistas tradicionais, reconhecimento formal desse setor na cogestão das área.

Com o plano de manejo aprovado pela CNPCT, a área protegida é criada com gestão compartilhada (direitos e responsabilidades) entre o conselho e a população extrativista. Esse arranjo propicia uma oportunidade para o desenvolvimento de processos cooperativos e compartilhados, que podem ser ajustados de acordo com as necessidades e dinâmicas socioecológicas locais (learning-by-doing) (Armitage et al., 2007). Os espaços e recursos marinhos passam, em tese, a serem reconhecidos pelas leis formais como áreas exclusivas para exploração comunitária dos pescadores artesanais organizados e os arranjos institucionais informais (sejam eles remanescentes, residuários, extintos ou embrionários) 
próprios da cultura local podem ser incorporados no plano de manejo.

Com a criação das primeiras Resex na década de 1990 (Alto Juruá e Chico Mendes) no estado do Acre, discussões sobre a implantação dessa categoria de área protegida para outros ecossistemas (Allegretti, 1994) foram iniciadas. A transposição das Resex para ambientes diversos dos florestais já era tema no final da década de 1980, mas, após a criação da primeira Resex fora dos limites amazônicos - a ResexMar de Pirajubaé (decreto $\mathrm{N}^{\circ} 533$ de 20/05/1992) em Santa Catarina -, grupos de pesquisadores debruçaram-se sobre a questão da viabilidade de transpor o modelo para regiões litorâneas para Guaraqueçaba, no Paraná, Mamanguape, na Paraíba, e Cananéia, em São Paulo.

Desde então, houve um aumento significativo de Resex e ResexMar no Brasil, que hoje conta com mais de $91 \operatorname{Resex}^{2}, 16$ delas nominalmente marinhas. Apesar de não nominadas, algumas das Resex listadas encontram-se em ambiente marinho (e.g. Resex Mandira em Cananéia e as três últimas criadas em 2018) e têm características distintas dos ambientes terrestres e contextos eminentemente florestais amazônicos. São diferenças não somente sob aspectos ecossistêmicos, como também relacionados às populações locais e diversidade de setores que atuam nas áreas costeiras e marinhas. Vejamos algumas delas.

\section{Da floresta para o mar: questões híbridas e diferenças}

Como destaca Cunha (2001), não há como promover a transposição mecânica do contexto florestal para os mares. Há implicações políticas, legais e socioambientais na delimitação de espaços marinhos exclusivos, havendo necessidade de ajustes conceituais, empíricos que irão influenciar na governança e na persecução dos objetivos sociais e ecológicos das ResexMar.

Concebidas como áreas para exploração sustentável e conservação dos recursos naturais por população extrativista, a eficiência dessa categoria de área protegida não está livre de críticas que entendem que as Resex se destinam à exploração monolítica dos recursos naturais, é economicamente desinteressante pelas margens de lucro obtidas, e acarretam impactos ambientais negativos sobre a diversidade e composição das espécies, além de promoverem marginalização social (Redford, 1992).

Tais críticas baseiam-se em grande medida no modelo de extrativismo realizado no período colonial, no qual as explorações desmedidas de recursos naturais (e.g. pau-brasil) exauriram solos, florestas e marginalizaram populações nativas. Existem motivações históricas para esse entendimento, mas sua perpetuação é anacrônica não somente pelo caráter de baixo para cima, resultante da resistência civil das populações extrativistas (Silveira, 2001) que ensejou na criação das Resex, mas também em razão dos estudos sobre manejo local dos recursos naturais nessas áreas, que demonstram que impactos socioecológicos negativos podem ser evitados e efeitos socioeconômicos positivos alcançados quando tecnologias e arranjos institucionais adequados são adotados.

No caso das ResexMar, autores apontam que a retirada do pescado do ambiente afeta diretamente a população da espécie, o que não ocorre, por exem-

\footnotetext{
${ }^{3}$ A lista consultada, ainda que relacione Resex federais e estaduais, não inseriu a Resex Marinha de Itaipu, criada em 2013 na esfera estadual, embora já constem as três últimas Resex criadas em abril 2018 (Itapetininga, Baía do Tubarão, Arapiranga-Tromai, todas na Amazônia Legal). https://uc.socioambiental.org/uso-sustentável/reserva-extrativista, acesso em abril/2018
} 
plo, com a extração da castanha ou da seringa em que as árvores permanecem vivas (Santos \& Schiavetti, 2013). Os autores elencaram ainda outros fatores que obstam o sucesso das ResexMar como: falta de monitoramento e grau de exploração dos recursos, número excessivo de extrativistas, artes de pesca não apropriadas aos organismos e habitats das espécies, manipulação política dos comunitários.

Em relação à governança, Jones et al. (2011) apontam para importantes diferenças entre as áreas protegidas (no-take ou de uso sustentável) criadas em ambientes terrestres e marinhos: i) escala de conectividade: devido à migração de grande parcela das espécies marinhas que ficam desprotegidas além dos limites espaciais das AMPs. Para os autores, essa questão está sendo desafiada com a ampliação de áreas que observam a conectividade dos ecossistemas marinhos; ii) incertezas: ecossistemas marinhos são mais complexos que os terrestres devido à variabilidade (maior quantidade de nichos e níveis tróficos) e compreensão insuficiente das estruturas e funções, sendo difícil justificar restrições de uso e acesso; iii) indiferentes e ocultos: para grande parcela da sociedade, os ecossistemas marinhos estão distantes e as espécies escondidas sob as ondas, o que dificulta a observação dos impactos negativos e alterações das paisagens marinhas. Há uma falta de compreensão histórica e consequente indiferença quanto às transformações e esgotamento das espécies marinhas; iv) naturalidade: a abordagem geral da gestão das AMPs é de não intervenção em comparação com a abordagem de gestão ativa para a conservação praticada em terra e intervenções são minimizadas, aplicando, em geral, restrição de certas atividades em determinadas áreas; e v) direito de apropriação: áreas e recursos marinhos nacionais têm direitos de uso e acesso pouco definidos e geralmente são reconhecidos como propriedade estatal.

Ainda que inúmeros estudos comprovem a existência de complexas combinações de apropriação dos espaços e recursos do mar (Johannes, 1982; Ruddle, 1989; Jentoft et al., 1998; Jentoft, 2004; Ruddle \& Hickey, 2007), principalmente em relação a arranjos coletivos, nota-se que o direito de apropriação privada é melhor reconhecido e aceito em ambientes terrestres em que as fronteiras e delimitação das áreas são melhor compreendidas que em áreas marinhas.

As Resex estabelecidas em ambientes marinhos, além de coexistirem com usos múltiplos, influenciam as políticas de uso na terra, uma vez que usuários diretos de recursos marinhos possuem uma vida anfíbia, ou seja, exercem atividades no mar, mas habitam e realizam outras atividades (inclusive produtivas, como, por exemplo, a agricultura familiar, extração de recursos florestais madeireiros e não madeireiros) na terra. Materiais necessários para realização do extrativismo marinho (e.g. embarcações, redes) são guardados em terra e não são raras as disputas pelo uso desses espaços (e.g. embarcações e redes de pesca que repousam na areia que também é ocupada por turistas, vendedores ambulantes, entre outros).

Pendleton et al. (2017) atentam para o fato de existirem muitos estudos experimentais e teóricos sobre os impactos biológicos das AMPs, mas que ainda temos muito a aprender sobre as dimensões sociais, gerenciais e políticas que afetam não somente o ambiente marinho, mas o ambiente terrestre, no qual muitas relações sociais são estabelecidas. Para Basurto (2017), a implantação de AMPs pode tanto auxiliar no aumento da cooperação entre os diversos tipos de usuários da área protegida e 
possibilitar incentivos para a gestão como ocorre com o monitoramento participativo, como também incentivar comportamentos antissociais que impedem as partes de se envolverem em atividades solidárias e de ajuda mútua.

Por outro lado, os desafios para eficiência social e ecológica das Resex são múltiplos. Diminuição da dependência de intermediários na inserção dos recursos naturais e seus derivados no mercado, aprimoramento da cadeia produtiva, agregação de valor aos produtos, melhoramento e dinamismo na gestão, aumento de investimentos e monitoramento participativo, agilidade na regularização fundiária e qualificação de recursos humanos para promoção do comanejo são alguns deles.

O fator populacional das Resex também deve ser considerado já que existe íntima relação entre baixa densidade demográfica e eficiência socioecológica das Resex, (Cunha \& Almeida, 2002), sejam elas marinhas ou terrestres. Um número excessivo de extrativistas, segundo Cunha \& Almeida (2002), dificulta a organização e convivência do grupo, retarda ou mesmo obsta a composição de arranjos e acordos para tomada de decisões, o que se reflete nas estratégias de conservação. Esse é um elemento importante para a reflexão da tentativa de criação de Resex em regiões onde a densidade demográfica (o que ocorre em áreas costeiras valorizadas ou próximas às regiões metropolitanas) é alta pelo custo social e ambiental que a exclusão dos não comunitários (segmentos que não possuem uma relação secular com os territórios marinhos, mas dele se utilizam para subsistência ou para realizar atividades comerciais não contemplados pela Resex) pode acarretar.

Nesse sentido, Pinkerton (2003) alerta que quanto maior o número e diversidade de vozes no sistema de manejo, maior o desafio do processo. Desafio, no entanto, não deve ser considerado um obstáculo a priori, já que essa mesma diversidade de participantes pode trazer para o sistema uma multiplicidade de conhecimentos, experiências e preocupações que de outra forma não seriam contemplados.

Em que pese o fato das Resex e ResexMar abrirem possibilidades, se não para a vigência do pluralismo legal $^{3}$ (Tie, 1999), ao menos para que o Estado reconheça a existência dos direitos consuetudinários dos comunitários nas áreas delimitadas, não se trata de uma panaceia e algumas condições socioecológicas que justifiquem sua criação devem ser observadas.

\section{Reflexões sobre arranjos institucionais na pesca de pequena escala e as ResexMar}

A marginalização histórica da pesca de pequena escala, atividade intimamente dependente dos recursos pesqueiros, associada à administração e regulamentação da pesca nacional pautada em interesses políticos e setoriais (como a pesca industrial), sofre efeitos ainda mais nefastos com o agravamento da crise planetária ambiental e dos estilos de desenvolvimento que concentram esforços em soluções de curto prazo.

Estudos internacionais e nacionais mostram que, entre populações de pescadores de pequena

\footnotetext{
${ }^{3}$ Pluralismo legal diz respeito à existência de leis de várias procedências sem que nenhuma seja hierarquicamente superior a outra.
} 
escala, regras informais (e.g. tabus, restrição de acesso, proibição de petrechos de pesca, respeito, reciprocidade, tamanho do pescado capturado, locais de pesca, direito de quem chega primeiro, regras de partilha e remuneração) por eles estabelecidas controlam o acesso e o uso dos recursos e contribuem para a sustentabilidade socioecológica (Johannes, 1982; Jentoft et al., 1998; Ruddle \& Hickey, 2007; Costa, 2011).

As regras são artefatos sociais e são tão diversas como são as sociedades humanas, mas existe um abismo entre a compreensão formal e a concepção pluralística do que é a lei. Esse conflito poderia ser diminuído caso a diversidade das necessidades humanas, adaptabilidade e transformações sociais fossem observadas. Relações sociais estabelecidas para apropriação dos espaços e recursos marinhos encontram-se alicerçadas em arranjos institucionais informais sofisticados e no conhecimento ecológico apurado. No caso dos recursos do mar, identificar as regras que delineiam o comportamento de pequenos pescadores (regras em uso) e os incentivos e desestímulos direcionados ao manejo dos recursos é fundamental para o sucesso das Resex como áreas de uso sustentável.

Reconhecer o pluralismo legal em Estados que repousam seu sistema legal sobre o centralismo jurídico, como é o caso brasileiro, no entanto, não é uma tarefa fácil. Também existem inúmeros obstáculos promovidos por setores hegemônicos da sociedade, cujos interesses privados ameaçam a cogestão de territórios marinhos por populações vulneráveis. Esse é o caso do Projeto de Lei $3068 / 2015$, que tramita na câmara dos deputados para, em nome da especulação imobiliária e da exploração da carcinicultura, transformar a ResexMar de Canavieiras criada no estado da Bahia em 2006 com benefício de aproximadamente 2.100 famílias de pescadores artesanais, agricultores familiares e fomento de turismo de base comunitária, em uma Área de Proteção Ambiental que permite usos múltiplos.

Pesquisas que tratam da noção de território e conceitos vizinhos como recursos, propriedade e territorialidade também discutem as dimensões em que as instituições informais de ação coletiva se alicerçam. No Brasil, aspectos relacionados à territorialidade e mobilização social dos pescadores sobre águas marinhas não protegidas também foram registrados (Forman, 1970; Cordell, 1989; Maldonado, 1993; Marques, 2001; Begossi, 2004), demonstrando a adequação de estratégias alternativas de organização de ações coletivas localizadas.

Formas locais de manejo pesqueiro podem ocorrer no interior ou fora de áreas protegidas, em águas costeiras, interiores, lagos, rios, estuários, mangues, entre outros ecossistemas e o estudo desses aspectos normativos vinculados à cultura local, suas motivações e comportamentos, pode indicar caminhos para a formulação de propostas mais adequadas de manejo. Para Johannes (1982), os direitos tradicionais de pesca, ao regularem comportamentos, podem não somente auxiliar na conservação dos estoques, como também minimizar conflitos e promover uma distribuição justa e efetiva dos recursos.

A falta de reconhecimento do poder público acerca dos arranjos informais, muito embora não obste sua existência e observância, confere às tomadas de decisão local uma condição de incerteza e vulnerabilidade. Para Pinkerton (2003), em arranjos de comanejo, o governo é um aliado potencial que pode prover suporte técnico, crédito e assistência comercial e possui autoridade para proteger os interesses dos participantes contra outros grupos. Já 
Jentoft et al. (2009) entendem que a interferência estatal mina os interesses comunitários.

Por outro lado, o poder público não é capaz $\mathrm{de}$, unilateralmente, assumir as responsabilidades e implicações envolvidas na conservação e monitoramento dos ecossistemas marinhos. Essa situação é dificultada no Brasil pelas dimensões da costa nacional e diversidade de comunidades pesqueiras existentes na costa (e.g. caiçaras, marisqueiras, ribeirinhos, quilombolas), cada qual com sua cultura e modos de apropriação dos recursos naturais marinhos.

Em esferas internas das comunidades locais, conflitos são em grande parte resolvidos por meio da aplicação de regras costumeiras que vigoram localmente e são apropriadas e adaptadas à cultura e identidade dos envolvidos. A gestão compartilhada estabelecida pelas ResexMar oferece uma oportunidade de inserir normas que seguem os costumes e tradições locais, inclusive no que diz respeito à graduação de sanções impostas pela não observância das regras locais. $\mathrm{O}$ fato da legitimação das instituições informais aumentar a participação ativa dos comunitários no processo de gestão e monitoramento dos recursos naturais colabora ainda para diminuir os custos com fiscalização e diminuir a aplicação de sanções (Jentoft, 1989; Hanna, 1998).

No que se refere à participação, Seixas \& Kalikoski (2009), em estudo para sistematizar a gestão participativa na pesca artesanal nacional (participação dos usuários diretos dos recursos nos processos de planejamento, implantação, monitoramento e avaliação do manejo), examinaram trabalhos de vários pesquisadores em diferentes partes do território nacional dirigidos aos graus de envolvimento dos usuários diretos nos processos de gestão (escalonado entre simples consultas até a total autonomia dos pescadores). As autoras verificaram que, quando comparada às estratégias de decisões centralizadas do Estado, a gestão participativa na pesca (muitas delas com a incorporação das regras locais) apresentava maior eficiência social e ecológica.

Nas Resex a gestão compartilhada é contemplada. Os beneficiários da delimitação da área e seus recursos, ou seja, as populações extrativistas tradicionais, têm como atividade principal para sobrevivência o extrativismo de recursos naturais que é executado de modo tradicional. Essa característica de tradicionalidade, no entanto, não pode estar engessada em critérios de paralisia tecnológica, ou seja, novas tecnologias, valorização dos recursos naturais utilizados, melhoria das condições da cadeia produtiva e comercialização que aumentem a sustentabilidade social e ecológica são desejadas e atividades consorciadas sustentáveis admitidas.

No caso das ResexMar há que se considerar que a costa nacional é altamente povoada e existem setores comprometidos com a exploração de petróleo, com a pesca de grande escala, fazendas marinhas, especulação imobiliária, entre outros segmentos. Além disso, muitas áreas marinhas contam com alto índice de poluição e atividades turísticas de interesses variados que disputam espaços com a pesca artesanal. Existem ainda questões de sobreposição de áreas protegidas não somente em escalas como de categorias diferentes (áreas protegidas de uso sustentável e áreas de proteção integral) que acarretam dúvidas sobre a legalidade das atividades em determinadas áreas e causam vários tipos de conflitos.

Nas ResexMar de Arraial do Cabo (Seixas, 2007) e de Itaipu (Costa, 2011), ambas no estado do Rio de Janeiro, foram elencados respectivamente 23 
e 20 conflitos distribuídos entre categorias de pescadores (que são divididos em diversos subgrupos), embarcações de recreação, associações diversas, atravessadores, turistas, surfistas, órgãos públicos, entre outros. Tais conflitos têm motivações variadas, em especial disputa por poder, por uso dos espaços e dos recursos do mar e minimizá-los requer esforço coletivo e comprometimento dos usuários, gestores e apoiadores.

Um elemento de destaque para o sucesso das áreas marinhas protegidas é o papel desempenhado pelas lideranças comunitárias. A fim de verificar em que condições o manejo de recursos naturais de uso comum (peixes em particular) pode ser bem-sucedido, Gutiérrez et al. (2011) levantaram 130 áreas de pesca onde vigora o comanejo (com envolvimento tanto na pesca artesanal como industrial). $\mathrm{O}$ trabalho englobou áreas de 44 países com ecossistemas e graus de desenvolvimento diversos. Como resultado os autores constataram que um dos mais importantes atributos para o sucesso desse tipo de gestão de recursos pesqueiros reside na proeminência de líderes comunitários.

Lideranças comunitárias realizam um papel fundamental para o comanejo. São elas, por exemplo, que incentivam os membros da comunidade a exercerem a cidadania e auxiliam no processo de inclusão, existindo, no entanto, a necessidade de formação contínua e horizontalidade para que processos de participação de todos os comunitários não sejam monopolizados individualmente.

A concentração da informação e imposição da vontade de uma liderança descaracteriza a razão legítima dos processos de criação de áreas protegidas de uso sustentável, uma vez que a reivindicação, conforme a gênese das Resex, depende do protagonismo comunitário e abordagens de cima para baixo impostas por universidades, gestores dos órgãos ambientais ou políticos, desviam-se dos propósitos legítimos dessas áreas, o que pode levar a insucessos e perda de credibilidade e confiança em iniciativas de comanejo e conservação (Pendleton et al., 2017).

Em Itaipu, por exemplo, Costa (2011) constatou que, desde as primeiras tentativas de criação da Resex, o órgão governamental auxiliado por departamentos acadêmicos não observou a necessidade de consolidação de lideranças comunitárias na organização e promoção de consensos para conduzir o processo. Após frustradas tentativas na esfera federal, a ResexMar de Itaipu foi criada em 2013 na esfera estadual por interferência política, sem que instrumentos alternativos para a gestão compartilhada dos recursos pesqueiros fossem discutidos. Outro fator preocupante é o estabelecimento de alianças e cooptação de lideranças da pesca de pequena escala por organizações não governamentais (ONGs) internacionais que, munidas de recursos externos, inserem metodologias já concebidas para a gestão da pesca artesanal, o que descaracteriza e coloca em risco a legitimidade do instrumento das Resex como fruto de mobilização social e gestão participativa.

Critérios da organização prévia dos comunitários para a formulação do pedido de criação de ResexMar devem ser observados, sendo necessário o apoio, mas não a imposição governamental ou de qualquer outra esfera. Organização e consenso em torno da criação de ResexMar levam tempo e o lapso temporal para o entendimento e tomada de decisão dos comunitários pode não corresponder aos prazos acadêmicos e de projetos do poder público ou organizações não governamentais. Há que se considerar também a existência de condições para conciliação de interesses (o que inclui o aspecto temporal), facilitadores preparados mobilizados e 
arranjos institucionais informais incluídos em todas as etapas do processo.

\section{Rumo ao futuro}

Nas seções anteriores procurou-se refletir sobre alguns desafios para a gestão compartilhada das ResexMar, as críticas a essa categoria de área protegida, peculiaridades de restrição de acesso a áreas e recursos naturais marinhos, interferências que obstam a autonomia, bem como a importância da participação dos comunitários e suas regras costumeiras na gestão das AMPs. Importante também, para o escopo deste material, apresentar proposições para aumentar as oportunidades e eficiências das ResexMar, já que somente a criação de áreas protegidas não garante proteção da biodiversidade ou das sociedades.

Há que se considerar que a sustentabilidade socioecológica é contextual e, sem a existência de sólidos alicerces organizacionais e institucionais, a criação de áreas protegidas, ainda que sejam preenchidas todas as formalidades legais, pode se tornar uma ficção, acirrar conflitos e impactar negativamente a qualidade dos ecossistemas e modo de vida das populações.

A primeira proposição refere-se às complementaridades e vantagens da hibridização do conhecimento local e técnico-científico para a promoção de desenvolvimento institucional comunitário. Bahia et al. (2018), em projeto realizado entre 2015 e 2016 com uma associação de barqueiros e pequenos pescadores do litoral sul do Rio de Janeiro, demonstraram a importância de apoio técnico-científico para facilitação, desde a concepção da iniciativa, de processos de aprendizagem recíproca e alcance de equilíbrio das relações entre poder público e comunitários.

Ressalta-se que esse apoio deve contribuir para valorizar os territórios pesqueiros e os produtos extrativistas em toda a cadeia produtiva. Ultrapassar efeitos meramente mercadológicos traz benefícios socioculturais que auxiliam o rompimento de relações subordinadas em que recursos naturais e territórios são expropriados para servir interesses hegemônicos e fornecimento de produtos primários.

Já a segunda proposição foi apontada por Chamy (2005) quanto à necessidade de articulação e promoção de intercâmbios entre as diferentes ResexMar para troca de experiências. A integração e experiências positivas e negativas das ResexMar são estratégias importantes para o fortalecimento institucional, desenvolvimento de conhecimento e estratégias capazes de produzirem resultados positivos, em especial para os pescadores que necessitam da praia e do mar como áreas de uso e reprodução social.

A organização para a criação de ResexMar leva tempo e condições para conciliação de interesses, mobilização e acesso homogêneo à informação devem ser promovidas. Mobilização legítima dos usuários e facilitadores preparados são necessários para a construção de um desenho institucional participativo e legítimo como pensado na gênese da criação desse instrumento de cogestão.

\section{Referências}

Aburto-Oropeza, O.; Erisman, B; Galland, G. R.; Mascareñas-Osorio, I.; Sala, E.; Ezcurra, E. Large recovery of fish biomass in a no-take marine reserve. Plos One, 12, 2011. doi: 10.1371/journal.pone.0023601 Allegretti, M. H. Reservas extrativistas: parâmetros para uma política 
de desenvolvimento sustentável na Amazônia. In: Arnt, R. (Org.). O destino da floresta: reservas extrativistas e desenvolvimento sustentável na Amazônia. Rio de Janeiro: Redume-Dumará, 1994.

Armitage, D.; Berkes, F.; Doubleday, N. Adaptive co-management: collaboration, learning and multi-level governance. Vancouver: UBC Press, 2007.

Bahia, N.; Chamy, P.; Rosa, I.; Almeida, L. Staying afloat. Samudra report, 78, 2018.

Basurto, X. Linking MPA effectiveness to the future of local rural fishing societies. ICES Journal of Marine Science, 2017, doi: 10.1093/icesjms/fsx075

Begossi, A. Áreas, pontos de pesca, pesqueiros e territórios na pesca artesanal. In: Begossi, A. (Org.). Ecologia de pescadores da Mata Atlântica e da Amazônia. São Paulo: HUCITEC/NEPAM/UNICAMP/NUPAUB/USP/FAPESP, 2004.

Carrière, J. P.; Cazella, A. A. Abordagem Introdutória ao conceito de Desenvolvimento Territorial. Eisforia, 4 (especial), 2006.

Chamy, P. Reservas extrativistas marinhas: um estudo sobre territorialidade marítima e sustentabilidade. Dissertação de Mestrado. Programa de Pós-Graduação em Ciência Ambiental/ PROCAM, Universidade de São Paulo, 2005.

Cordell, J. A sea of small boats. Massachusetts: Cultural Survival, 1989.

Costa, P. C. P. Interações socioecológicas na pesca à luz da Etnoecologia Abrangente: a praia de Itaipu, Niterói/ RJ. Tese de Doutorado do Programa de Pós-Graduação em Ambiente e Sociedade/NEPAM, Universidade Estadual de Campinas, 2011.

Cunha, L. H. Reservas extrativistas: uma alternativa de produção e conservação da biodiversidade. Encontro dos Povos do Vale do Ribeira. São Paulo, 2001.

Cunha, M.; Almeida, M. Enciclopédia da floresta: o Alto Juruá, práticas e conhecimentos das populações. São Paulo: Cia das Letras, 2002.

Diegues, A. C. Marine protected areas and artisanal fisheries in Brazil. Samudra Monograph. Índia: ICSF, 2008.
Earle, S. A terra é azul. Por que o destino dos oceanos e o nosso é um só? São Paulo: Sesi-SP editora, 2017.

Edgar, G. et al. Global conservation outcomes depend on marine protected areas with five key features. Nature, 2014. doi: 10.1038/nature13022Forman, S. The raft fishermen: tradition and change in the Brazilian peasant economy. Indiana: Indiana University Press, 1970.

Gutiérrez, N.; Hilborn, R.; Defeo, O. Leadership, social capital and incentives promote successful fisheries. Nature, (09689), 2011.

Halpern, B.; Warner, R. Marine reserves have rapid and lasting effects. Ecology letters, 5(3), 2002. doi: 10.1046/j. 1461-0248.2002.00326.x

Hanna, S. Managing for human and ecological context in the Maine soft shell clam fishery. In: Berkes, F.; Folke, C. Linking social and ecological systems. Cambridge: University Press, 1998.

IPBES - Intergovernmental Science-Policy Platform on Biodiversity and Ecosystem Services, 2018.

IUCN - International Union for Conservation of Nature. http://www.iucn.org/about/union/commissions/wcpa/ wcpa_what/wcpa_marine/wcpa_marineaction/. Acessado em maio/2012.

Jentoft, S. Fisheries co-management: delegating government responsibility to fishermen's organizations. Marine Police, 13, 1989.

Jentoft, S. Institutions in fisheries: what they are, what they do and how they change. Marine Policy, 28, 2004.

Jentoft, S.; Bavinck, M.; Johnson, D.; Thomson, K. Fisheries co-management and legal pluralism: how an analytical problem becomes an institutional one. Human Organization, 68(1), 2009.

Jentoft, S.; McCay, B.; Wilson, D. Social theory and fisheries co-management. Marine Police, 22, 1998.

Johannes, R. E. Traditional conservation methods and protected marine areas in Oceania. Ambio, 2(5), 1982.

Jones, P.; Qiu, W.; de Santo, E. Governing Marine Protected Areas: Getting the Balance Right. Technical Report, Nairobi: UNEP, 2011. 
Maldonado, S. C. Mestres \& Mares: espaço e indivisão na pesca marítima. São Paulo: Annablume, 1993.

Marques, J. G. W. Pescando pescadores: ciência e etnociência em uma perspectiva ecológica. 2a. ed. São Paulo: NUPAUB/USP, 2001.

Mendes, C. A luta dos povos da floresta. Geografia, pesquisa e prática social. Revista Terra Livre, São Paulo: Marco Zero, n.7, abril, 1990.

Pendleton, L.; Ahmadia, G.; Browman, H.; Thurstan, R.; Kaplan, D.; Bartolino, V. Debating the effectiveness of marine protected areas. ICES Journal of Marine Science, 2017. doi: 10.1093/icesjms/fsx154Pinkerton, E. Toward Specificity in Complexity: Understanding Co-Management from a Social Science Perspective. In: Wilson, D. G.; Nielsen, J. R.; Degnbol, P. (Eds.). The Fisheries Co-management Experience: Accomplishments, Challenges and Prospects. Kluwer: Dordrecht, 2003.

Redford, K. “The empty forest”. Bioscience, 42, 1992.

Roberts, C. The unnatural history of the sea. Washington: Island Press, 2007.

Ruddle, K. Solving the common property dilemma: village fisheries rights in Japanese coastal waters. In: Berkes, F. (Ed.). Common-property resources: ecology and community-based sustainable development. London: Belhaven Press, 1989.

Ruddle, K.; Hickey, F. Accounting for the mismanagement of tropical nearshore fisheries: tropical fisheries mismanagement. Annais da XVth International Conference of the Society for Human Ecology, 2007.

Sabine, C. L. et al. The oceanic sink for anthropogenic CO2. Science, 305, 2004.

Santos, C.; Schiavetti, A. Reservas extrativistas marinhas do Brasil: contradições de ordem legal, sustentabilidade e aspecto ecológico. Boletim do Instituto de Pesca, 39(4), 2013.

Seixas, C. S. Dinâmicas sócio-ecológicas em gestão pesqueira participativa: o caso de uma Reserva Extrativista Marinha. Relatório de Pós-Doutorado. Universidade Estadual de Campinas, 2007.

Seixas, C. S.; Kalikoski, D. Gestão participativa da pesca no Brasil: levantamento das iniciativas e documentação dos processos. Desenvolvimento e Meio Ambiente, 20, 2009.

Silveira, P. C. B. Povo da terra, terra do parque: presença humana e conservação de florestas no Parque Estadual Turístico do Alto Ribeira, SP. Dissertação de Mestrado do Departamento de Antropologia do IFCH/UNICAMP, 2001.

Steward, G. B. et al. Temperate marine reserves: global ecological effects and guidelines for future networks. Conservation Letters, 2, 2009.

Tie, W. Legal pluralism: toward a multicultural conception of law. Aldershot: Dartmouth Publishing Company Limited, 1999. 